
\title{
25 Research Soure \\ First case of COVID-19 infection in a adult patient with Ellis-van Creveld Syndrome
}

\section{Isabelle Piazza}

ASST Papa Giovanni XXIII: Aziende Socio Sanitarie Territoriale Papa Giovanni XXIII

Paolo Ferrero ( $\square$ ferrerop41@gmail.com )

Aziende Socio Sanitarie Territoriale Papa Giovanni XXIII https://orcid.org/0000-0001-7967-7417

\section{Case Report}

Keywords: Ellis-van Creveld, COVID-19, SARS CoV-2, congenital heart disease

Posted Date: February 23rd, 2021

DOI: https://doi.org/10.21203/rs.3.rs-237427/v1

License: (c) (i) This work is licensed under a Creative Commons Attribution 4.0 International License. Read Full License 


\section{Abstract}

Background: Ellis-van Creveld syndrome (EVC) is a rare autosomal recessive disorder, the features of the syndrome are: chondral and ectodermal dysplasia characterized by short ribs, polydactyly, growth retardation resulting in dwarfism, teeth and craniofacial abnormalities and heart defects (mostly endocardial cushions and atrial septal defects).

Case presentation: We describe the first case of COVID-19 infection in a 24-years-old girl, diagnosed with EVC syndrome. The patient suffered only from a mild illness, she remained stable with normal saturation without need of neither respiratory support nor specific therapy and she was rapidly discharged.

Conclusions: This case appraises the pathophiosiologic interplay between different specific prognostic variable in a syndromic patient with congenital heart disease and COVID-19.

\section{Background}

Ellis-van Creveld syndrome (EVC) is a rare autosomal recessive disorder, firstly described in 1940 by Richard W.B. Ellis and Simon Van Creveld. (1) It is caused by mutations in the EVC or EVC2 genes located on the chromosome 4, coding for components of the primary cilia, and is associated to parental consanguinity in about $30 \%$ of cases. (2-4)

EVC syndrome, like Jeune asphyxiating thoracic dysplasia (JATD), is part of the skeletal ciliopathies, sharing common clinical and radiological features. There is a large spectrum of severity in skeletal involvement, however, differently from JATD, extreme thoracic hypoplasia is rare in EVC. (5)

The EVC syndrome features include chondral and ectodermal dysplasia characterized by short ribs, polydactyly, growth retardation resulting in dwarfism, teeth and craniofacial abnormalities and heart defects. (6-8) The prevalence of cardiac anomalies in patients with EVC syndrome has been estimated to affect $60 \%$ of individuals. (9) The cardiac phenotype in patients with EVC syndrome reveals a characteristic pattern of atrioventricular canal defects (AVCD) with systemic and pulmonary venous connection abnormalities and common atrium (10)

\section{Case Description}

We describe the first case of COVID-19 infection in a 24-years-old girl, diagnosed with EVC syndrome. She had undergone ostium primum atrial septal defect repair at age of five, genu valgum deformity correction and tibial lengthening at the age of eleven. (11) At age of ten, she was prescribed growth hormone for $\mathrm{GH}$ deficit, that she stopped due to headache. (12) The patient displayed all the somatic syndromic signs, including theet agenesia, short lingual frenulum and obesity. In addition she was on chronic Cortone Acetate because of lichen planus. 
The patient presented to the emergency department with fever and dry cough lasting for the last two days. She was eupnoic at rest with normal respiratory rate and chest findings on physical examination. BMI was 28. Oxygen saturation in room air was $98 \%$. Laboratory findings were: Hemoglobin $125 \mathrm{~g} / \mathrm{L}$, WBC 5.65 10^9/L, Na $141 \mathrm{mmol} / \mathrm{L}, \mathrm{K} 4.1 \mathrm{mmol} / \mathrm{L}, \mathrm{CRP} 0.2 \mathrm{mg} / \mathrm{dl}$, creatinine $0.60 \mathrm{mg} / \mathrm{dl}$, GOT $21 \mathrm{U} / \mathrm{L}$, GPT 27 U/L, LDH 202 U/L. The chest-X-Ray beside showing reduced thoracic diameters was unremarkable, in particular lung transparency was normal (Figure 1).

The ECG showed sinus rhythm, first degree AV block, left anterior fascicular block and occasional ventricular ectopics consistent with the underlying congenital anatomy (Figure 2).

During admission the patient remained stable with normal saturation without need of neither respiratory support nor specific therapy. She was discharged after five days and the nasopharyngeal swab became negative after fifteen days.

\section{Discussion}

AVCDs and common atria are usually associated with EVC, suggesting a developmental defect in endocardial cushions. Although primary pulmonary involvement has not been reported in association with Ellis-van Creveld syndrome, respiratory function may be affected by skeletal abnormalities of the thoracic cage. Both cardiac and extra cardiac involvement may affect clinical presentation and severity of COVID-19.

This case offer several pathophyisiological issues to discuss. The patient had undergone partial atrioventricular septal defect repair at the age of five, therefore we can speculate that exposition to pulmonary over-circulation might have altered vascular reactivity. Furthermore the association of EVC syndrome with pulmonary vascular disease has been reported. (10) So far there are no evidences suggesting increase susceptibility to SARS CoV-2 or a worse prognosis of the infection in adults with CHD. (13.14) More importantly, scheletric chest abnormalities, reduced vital capacity and increased BMI in EVC syndrome are relevant comorbidities which might potentially affect in many different ways clinical course of COVID-19. (15)

Kidneys and liver are other uncommon end organs involved in EVC characterized by glomerular and tubular degeneration and periportal fibrosis, respectively. (16) Although we do not have evidence of renal or hepatic failure in our patient, the aforementioned histologic abnormalities may be subclinical and can be responsible for reduced functional reserve that might be unmasked by COVID-19 infection.

On the other hand the patient displayed some clinical characteristic that might be considered protective. In particular female gender and young age are recognized as aspecific favorable demographic variables. (17) Furthermore chronic steroid therapy with Cortone acetate might have blunted the inflammatory storm which is deemed to be a crucial pathophysiologic mechanism sustaining lung injury (Figure 3 ). 


\section{Conclusion}

In conclusion we present the first case of COVID-19 in a patient with EVC syndrome. Data on the impact of CHD and syndromes on COVID-19 clinical course are still very scant. This report support the concept arising from preliminary data suggesting that, among CHD patients, the outcome of SARS CoV-2 infection is shaped by the complex interaction of patient specific variables, rather than by the preexisting cardiac condition. (13)

\section{Abbreviations}

EVC Ellis-van Creveld

JATD Jeune asphyxiating thoracic dysplasia

WBC white blood cells

CRP C-reactive protein

AVCD atrioventricular canal defect

ASD atrial septal defect

CHD Congenital heart disease

\section{Declarations}

Ethics approval and consent to participate: obtained

Consent for publication: obtained

Availability of data and materials: N/A

Competing interests: none

Funding: none

Authors' contributions: Dr Isabelle Piazza collects the data and write the paper.

Dr Paolo Ferrero reviewed and approved the final manuscript.

Acknowledgements: none

\section{References}

1. OMIM Online Mendelian Inheritance in Man, no. 225500 
2. Ruiz-Perez VL, Ide SE, Strom TM, Lorenz B, Wilson D, Woods K et al (2000) Mutations in a new gene in Ellis-van Creveld syndrome and Wyers acrodental dystosis. Nature Genet 24:283-86.

3. Ruiz-Perez VL, Tompson SWJ, Blair HJ, Espinoza-Valdez C, Lapunzina P, Silva EO et al (2003) Mutations in two nonho- mologous genes in a head-to-head configuration cause Ellis-van Creveld syndrome. Am J Hum Genet 72:728-32.

4. Shetty P, Shetty D, Priyadarshana PS, Bhat S. A rare case report of Ellis Van Creveld syndrome in an Indian patient and literature review. Oral Biol Craniofac Res. 2015;5:98-101.

5. Handa A, Voss U, Hammarsjö A, Grigelioniene G, Nishimura G. Skeletal ciliopathies: a pattern recognition approach. Jpn J Radiol. 2020;38:193-206.

6. Baujat G, Le Merrer M. Ellis-van Creveld syndrome. Orphanet J Rare Dis. 2007;2:27.

7. Katsouras CS, Thomadakis C, Michalis LK. Cardiac Ellis-van Creveld syndrome. Int J Cardiol. 2003;87:315-6.

8. Peña-Cardelles JF, Domínguez-Medina DA, Cano-Durán JA, Ortega-Concepción D, Cebrián JL. Oral manifestations of ellis-van creveld syndrome. A rare case report. J Clin Exp Dent. 2019;11:e290-5.

9. Smith DW. Smith's recognizable patterns of human malformations. Lyon Jones K editor. 6th ed. Elsevier Saunders: Philadelphia; 2006.

10. Hills CB, Kochilas L, Schimmenti LA, Moller JH. Ellis-van Creveld Syndrome and Congenital Heart Defects: Presentation of an Additional 32 Cases. Pediatr Cardiol 2011;32:977-82

11. Weiner DS, Tank JC, Jonah D, Morscher MA, Krahe A, Kopits S, Schrader WC. An operative approach to address severe genu valgum deformity in the Ellis-van Creveld syndrome. J Child Orthop. 2014;8:61-9

12. Versteegh FGA, Buma SA, Costin G, de Jong WC, Hennekam RCM, EvC Working Party. Growth hormone analysis and treatment in Ellis-van Creveld syndrome. Am J Med Genet A 2007;143A:211321

13. Ferrero P, Piazza I, Ciuffreda M. COVID-19 in adult patients with CHD: a matter of anatomy or comorbidities? Cardiol Young. 2020;30:1196-98

14. Sabatino J, Ferrero P, Chessa M, Bianco F, Ciliberti P, Secinaro A, Oreto L, Avesani M, Bucciarelli V, Calcaterra G, Calabrò MP, Russo MG, Bassareo PP, Guccione P, Indolfi C, Di Salvo G. COVID-19 and Congenital Heart Disease: Results from a Nationwide Survey. J Clin Med. 2020;9:1774

15. Hoong CWS, Hussain I, Aravamudan VM, Phyu EE, Lin JHX, Koh H. Obesity is Associated with Poor Covid-19 Outcomes: A Systematic Review and Meta-Analysis. Horm Metab Res. 2021 Jan 4. doi: 10.1055/a-1326-2125. Online ahead of print.

16. Böhm N, Fukuda M, Staudt R, Helwig H. Chondroectodermal dysplasia (Ellis-van Creveld syndrome) with dysplasia of renal medulla and bile ducts. Histopathology 1978;2:267-81.

17. Ancochea J, Izquierdo JL, Soriano JB. Evidence of Gender Differences in the Diagnosis and Management of Coronavirus Disease 2019 Patients: An Analysis of Electronic Health Records Using 
Natural Language Processing and Machine Learning. J Womens Health (Larchmt). 2020 Dec 16. doi: 10.1089/jwh.2020.8721. Online ahead of print.

18. RECOVERY Collaborative Group, Horby P, Lim WS, Emberson JR, Mafham M, Bell JL, Linsell L, Staplin N, Brightling C, Ustianowski A, Elmahi E, Prudon B, Green C, Felton T, Chadwick D, Rege K, Fegan C, Chappell LC, Faust SN, Jaki T, Jeffery K, Montgomery A, Rowan K, Juszczak E, Baillie JK, Haynes R, Landray MJ. Dexamethasone in Hospitalized Patients with Covid-19 - Preliminary Report. N Engl J Med. 2020 Jul 17:NEJMoa2021436. doi: 10.1056/NEJMoa2021436. Online ahead of print.

\section{Figures}

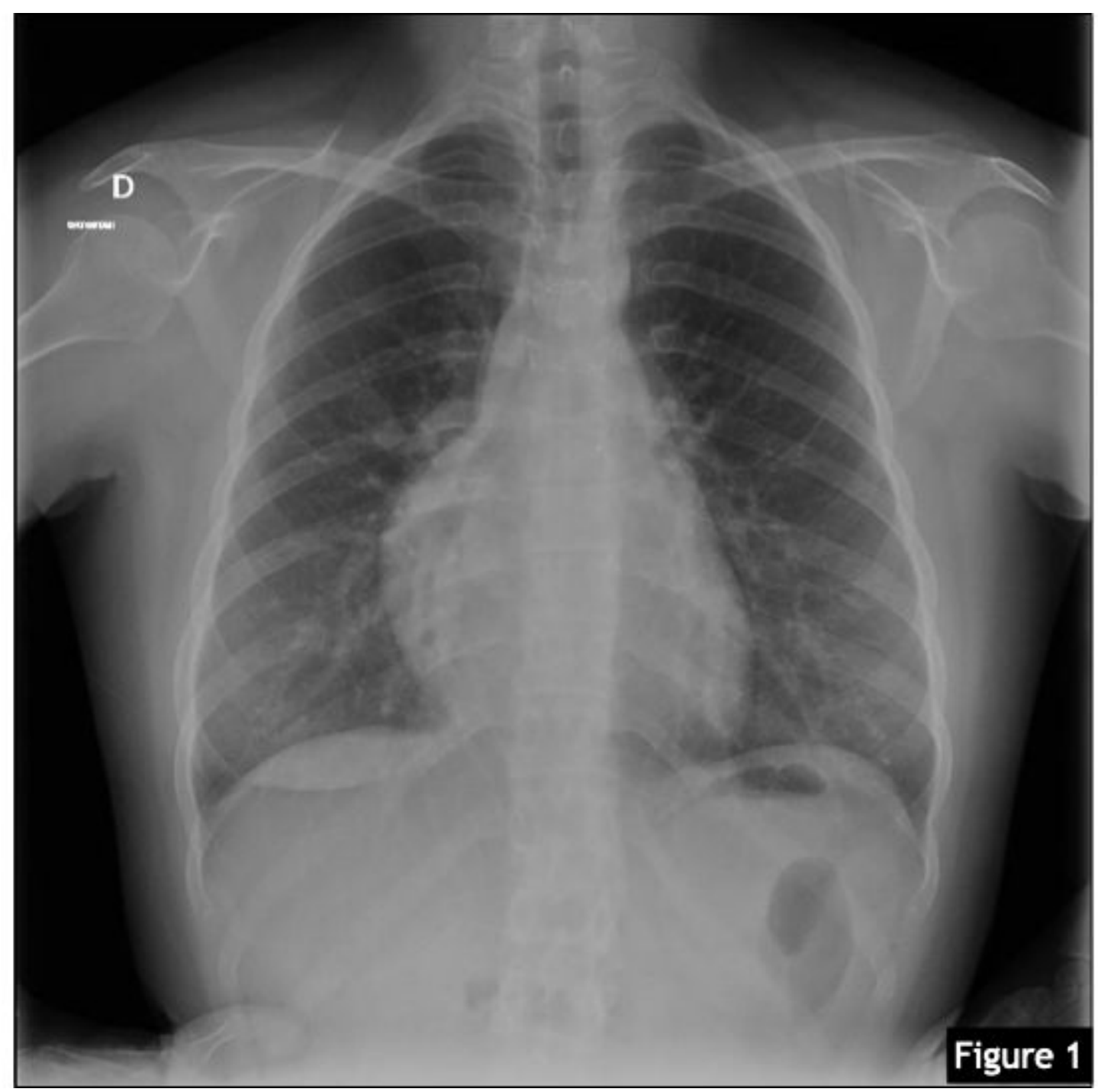

\section{Figure 1}

Chest $\mathrm{X}$ ray at admission 


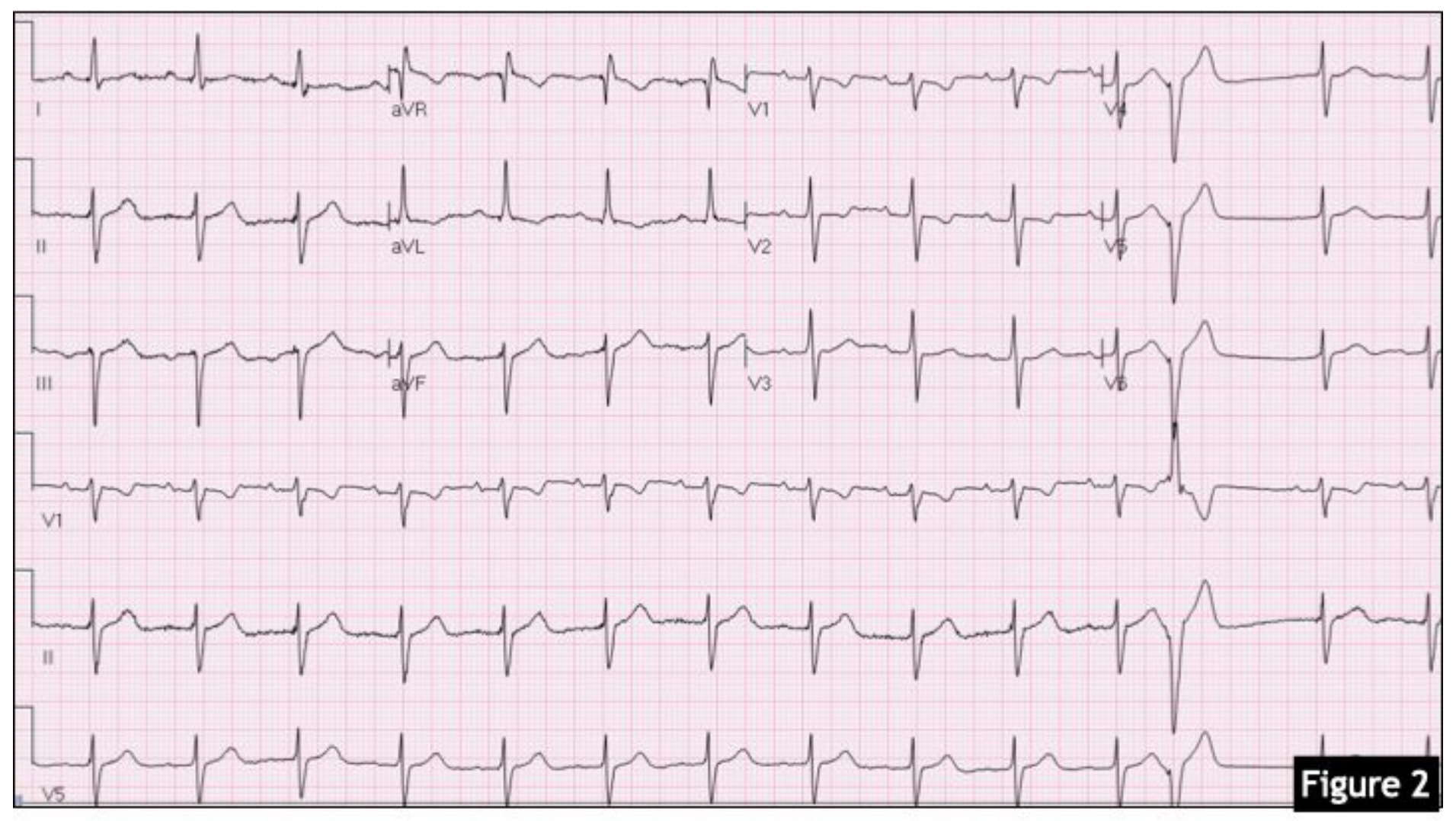

Figure 2

ECG tracing at admission 


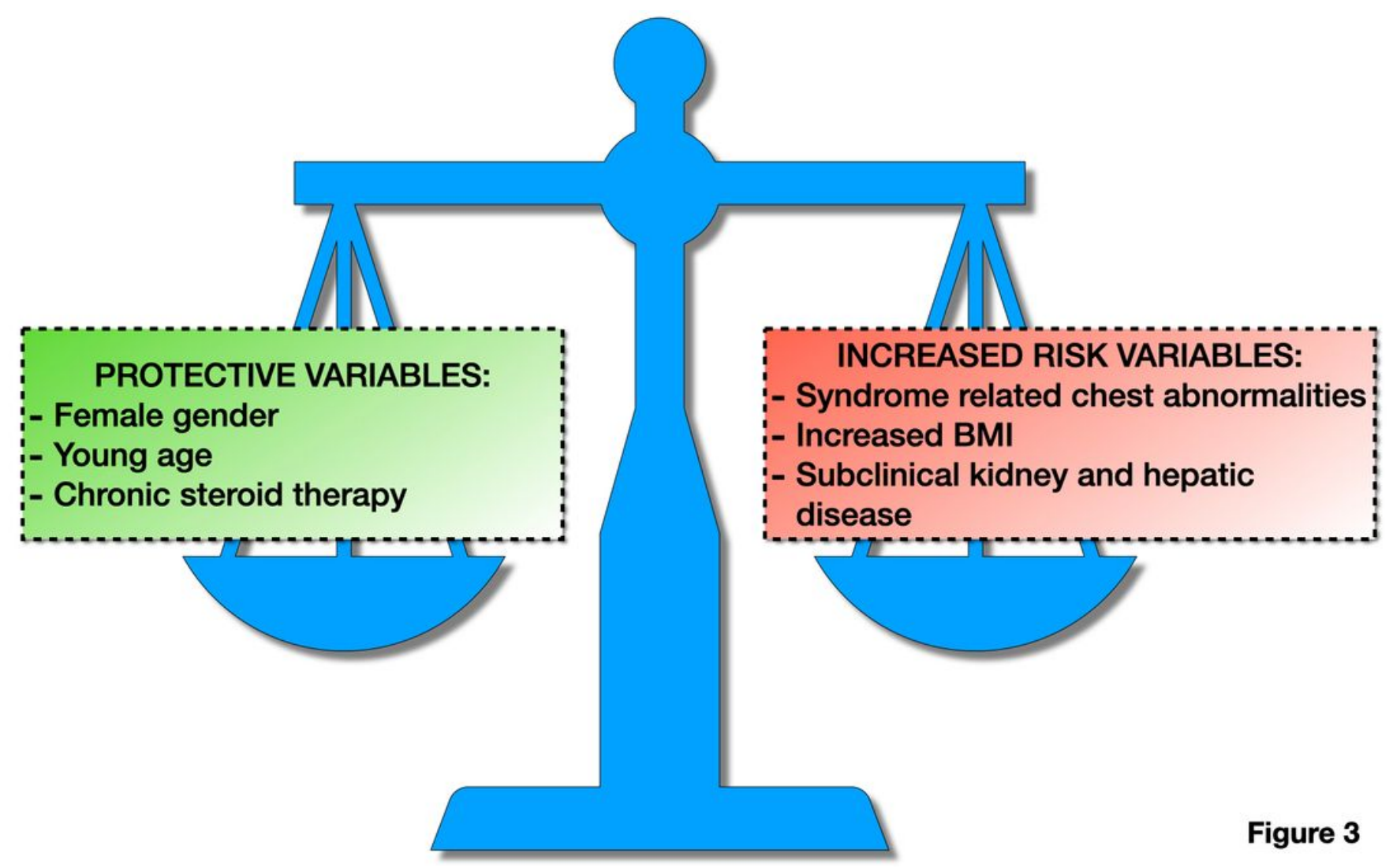

Figure 3

Diagram summarizing specific variable potentially modulating the risk in EVC syndrome 